\title{
AIP-mutated acromegaly resistant to first-generation somatostatin analogs: long-term control with pasireotide LAR in two patients
}

\author{
Adrian F Daly1,*, Liliya Rostomyan', , Daniela Betea ${ }^{1}$, Jean-François Bonneville1, Chiara Villa ${ }^{1,2}$, Natalia S Pellegata ${ }^{3}$ \\ Beatrice Waser ${ }^{4}$, Jean-Claude Reubi ${ }^{4}$, Catherine Waeber Stephan ${ }^{5}$, Emanuel Christ ${ }^{6, \dagger}$ and Albert Beckers ${ }^{1, \dagger}$

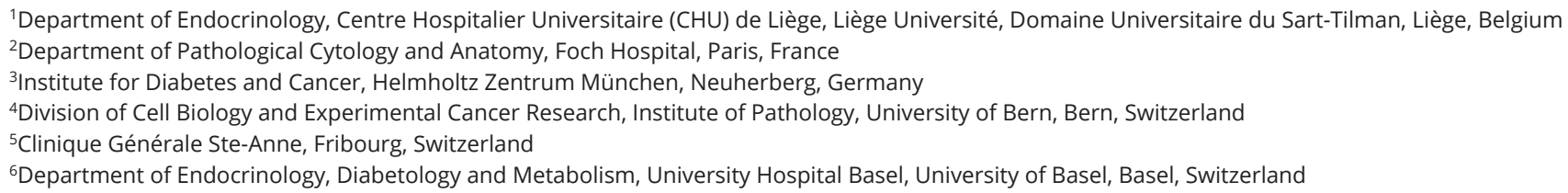

\section{Abstract}

Acromegaly is a rare disease due to chronic excess growth hormone $(\mathrm{GH})$ and IGF-1. Aryl hydrocarbon receptor interacting protein $(A I P)$ mutations are associated with an aggressive, inheritable form of acromegaly that responds poorly to SST2-specific somatostatin analogs (SSA). The role of pasireotide, an SSA with affinity for multiple SSTs, in patients with AIP mutations has not been reported. We studied two AIP mutation positive acromegaly patients with early-onset, invasive macroadenomas and inoperable residues after neurosurgery. Patient 1 came from a FIPA kindred and had uncontrolled GH/IGF-1 throughout 10 years of octreotide/lanreotide treatment. When switched to pasireotide LAR, he rapidly experienced hormonal control which was associated with marked regression of his tumor residue. Pasireotide LAR was stopped after $>10$ years due to low IGF-1 and he maintained hormonal control without tumor regrowth for $>18$ months off pasireotide LAR. Patient 2 had a pituitary adenoma diagnosed when aged 17 that was not cured by surgery. Chronic pasireotide LAR therapy produced hormonal control and marked tumor shrinkage but control was lost when switched to octreotide. Tumor immunohistochemistry showed absent AIP and SST2 staining and positive SST5. Her AIP mutation positive sister developed a $2.5 \mathrm{~cm}$ follicular thyroid carcinoma aged 21 with tumoral loss of heterozygosity at the AIP locus and absent AIP staining. Patients 1 and 2 required multi-modal therapy to control diabetes. On stopping pasireotide LAR after $>10$ years of treatment, Patient 1's glucose metabolism returned to baseline levels. Long-term pasireotide LAR therapy can be beneficial in some AIP mutation positive acromegaly patients that are resistant to first-generation SSA.

\section{Key Words}

- acromegaly

- AIP

- somatostatin analog

- FIPA

- resistant

- pituitary adenoma

- pasireotide

- octreotide

- lanreotide

- thyroid cancer https://ec.bioscientifica.com https://doi.org/10.1530/EC-19-0004 (c) 2019 The authors Published by Bioscientifica Ltd
Endocrine Connections (2019) 8, 367-377 


\section{Introduction}

Acromegaly is a rare, classical endocrine disorder that is due to chronic excess secretion of growth hormone (GH) and insulin-like growth factor 1 (IGF-1) that has a prevalence of 1 in $8000-14,000$ of the population $(1,2,3,4)$. A somatotropinoma of the anterior pituitary gland is the predominant cause of acromegaly. In the largest international series of $>3100$ patients, acromegaly presented at a median age of 45.2 years, and was slightly more common in women (54.5\%) (5). The pituitary tumors in acromegaly are generally macroadenomas ( $>10 \mathrm{~mm}$ in diameter), and nearly half of patients have local tumor invasion at diagnosis.

Many studies have examined the molecular genetic pathophysiology of acromegaly. The best-known molecular change underlying somatotropinomas are somatic activating mutations of GNAS that are present in up to $40 \%$ of tumors (6). Inheritable germline genetic mutations are considerably rarer and acromegaly can occur as part of multi-organ tumor syndromes such as multiple endocrine neoplasia type 1 (MEN1), McCuneAlbright Syndrome (MAS), Carney complex, and the emerging pheochromocytoma-paraganglioma-pituitary adenoma association (3PA) (7). Mutations in the aryl hydrocarbon receptor interacting peptide (AIP) gene account for the largest proportion of genetic/inheritable forms of acromegaly. Among unselected acromegaly populations, $0-4 \%$ of patients have AIP mutations/ deletions, which rises in more focused groups such as familial isolated pituitary adenoma (FIPA) kindreds and young patients, reaching nearly $30 \%$ in those with pituitary gigantism (8). AIP mutations confer a series of important aggressive characteristics in acromegaly. As compared with non-mutated acromegaly patients, those with AIP mutations have a statistically significantly younger age at onset, larger tumor size, and higher GH secretion $(9,10)$. Importantly, treatment of acromegaly in AIP-mutated patients is more difficult due to this aggressive disease profile; in particular those with AIP mutations have a significantly lower hormonal response to first-generation, receptor subtype 2 (SST2) specific somatostatin analogs (octreotide and lanreotide) and have a decreased rate of tumor shrinkage on treatment (9). The molecular mechanism for this relative somatostatin analog resistance may occur via Gai proteins or ZAC1, which are themselves important mediators of SST2 actions $(11,12,13)$. Given the relatively poor results achieved with first-generation somatostatin analogs in patients with AIP mutations, the role of other agents such as the
GH receptor antagonist pegvisomant has been described in those with AIP mutations (14). Pasireotide is a newer somatostatin analog that is approved for use in patients that are resistant to first-generation agents (15). It has a high affinity for multiple SSTs, including SST2, SST3 and SST5, which permits significantly improved control in those resistant to octreotide/lanreotide (16). Despite the well-known resistant profile of AIP mutation acromegaly patients, little specific information is available on the use of pasireotide in this distinct subgroup of aggressive disease. Here we discuss our long-term experience in two patients with different germline AIP mutations who were resistant to octreotide and lanreotide but that had hormonal control and/or tumor shrinkage on pasireotide therapy.

\section{Methods}

\section{Genetic testing}

Patients and their families provided informed written consent for genetic testing, which was performed under an approval of the Ethics Committee of the Centre Hospitalier Universitaire de Liège.

\section{Immunohistochemistry}

AIP immunostaining of paraffin preserved tumor tissue (pituitary in Patient 2 and thyroid cancer in the sister of Patient 2) was performed with a monoclonal IgG antibody (Novus Biological, Cambridge, UK) at dilutions of 1:500-1:1000. Pituitary tumor tissue from surgery in 1994 was no longer available for Patient 1 . Somatostatin receptor immunohistochemistry was performed according to Körner et al. (17). The primary antibodies were as follows: SST2 (clone UMB-1 (SST2a isoform), dilution: 1/500), SST3 (clone UMB-5, dilution: 1/750), SST5 (clone UMB-4, dilution: 1/75) were purchased from Abcam (Cambridge, MA, USA).

\section{Patients and results}

\section{Patient 1}

In 1994, a 29-year-old male patient first attended the ophthalmologist with discomfort in the left sub-orbital area and blurred vision of the left eye for several weeks. He also complained of numbness on the right side of his face, headache and fatigue. Ophthalmological evaluation revealed bitemporal hemianopia, more pronounced on 
the left side. Pituitary MRI was performed showing a pituitary macroadenoma measuring $25 \mathrm{~mm}$ in its largest diameter, compressing the optic chiasma and invading in the right cavernous sinus. He was referred to our clinic and on examination had acral enlargement, prognathism, macroglossia, thickened skin, deep voice, and increased sweating, consistent with acromegaly. He was $175 \mathrm{~cm}$ in height and had normal growth patterns in childhood and adolescence; his parents were of normal height (Fig. 1). His body mass index was BMI $30 \mathrm{~kg} / \mathrm{m}^{2}$ and he was normotensive. Laboratory tests revealed increased random GH $(3.3 \mathrm{ng} / \mathrm{mL})$ and IGF-1 $(1116 \mathrm{mg} / \mathrm{mL}$; normal range: $85-218)$, and hyperprolactinemia $(739 \mathrm{mIU} / \mathrm{L}$; Fig. 2A). Other biochemical and hormonal profiles were normal apart from the presence of impaired glucose tolerance. He underwent a transsphenoidal resection of the accessible pituitary tumor mass, but a sizable $(16 \mathrm{~mm})$ tumor remnant adjoining the right cavernous sinus could not be accessed surgically (Fig. 2B). Pathology studies showed a pituitary adenoma with positive immunostaining for $\mathrm{GH}$ and prolactin. Postoperatively the patient had deficiencies in the thyrotrope and gonadotrope axes and he received supplementation. During follow-up, Patient 1 had elevated GH/IGF-1 levels and he was treated with octreotide, first as a three times daily subcutaneous injection (Fig. 2). Over the following 10 years, he received long-acting forms of lanreotide and octreotide up to the maximum doses. Clinically, the patient experienced partial symptomatic benefits from the SSA treatment but IGF-1 levels were uncontrolled. Addition of a dopamine agonist did not improve his control. His impaired glucose tolerance worsened and he was diagnosed with type 2 diabetes mellitus that required treatment with metformin. Over the following years there was evidence of tumor expansion during somatostatin analog treatment. The patient declined radiotherapy and reoperation and he remained uncontrolled through to 2006; pegvisomant treatment, when it became available, was also declined due to the incomplete control of tumor size on a somatostatin analog.

In 2006 the patient discontinued first-generation somatostatin analogs and began pasireotide LAR $30 \mathrm{mg} / \mathrm{month}$ as part of a research study. Following up-titration to $60 \mathrm{mg}$, monthly GH and IGF-1 levels were normalized and the patient reported improvement in clinical signs and symptoms of acromegaly (Fig. 2). Serial MRIs showed significant and continuing tumor shrinkage, even after pasireotide LAR dose was optimized at $40 \mathrm{mg} / \mathrm{month}$ (Fig. 2C). By 2013 his GH and IGF-1 remained controlled and MRI showed an empty sella and a small intrasellar tumor remnant. Pasireotide LAR treatment was associated with worsening of existing diabetes. Before beginning pasireotide his $\mathrm{HbA1c}$ had been $6.2 \%$ on metformin and a thiazolidinedione, but rose to $8.8 \%$ on pasireotide despite various combined drug therapies including metformin, dipeptiyl peptidase- 4 (DPP-4) inhibitors, a sulfonylurea and GLP-1 agonists. HbA1c was eventually brought down to $<7 \%$ with the
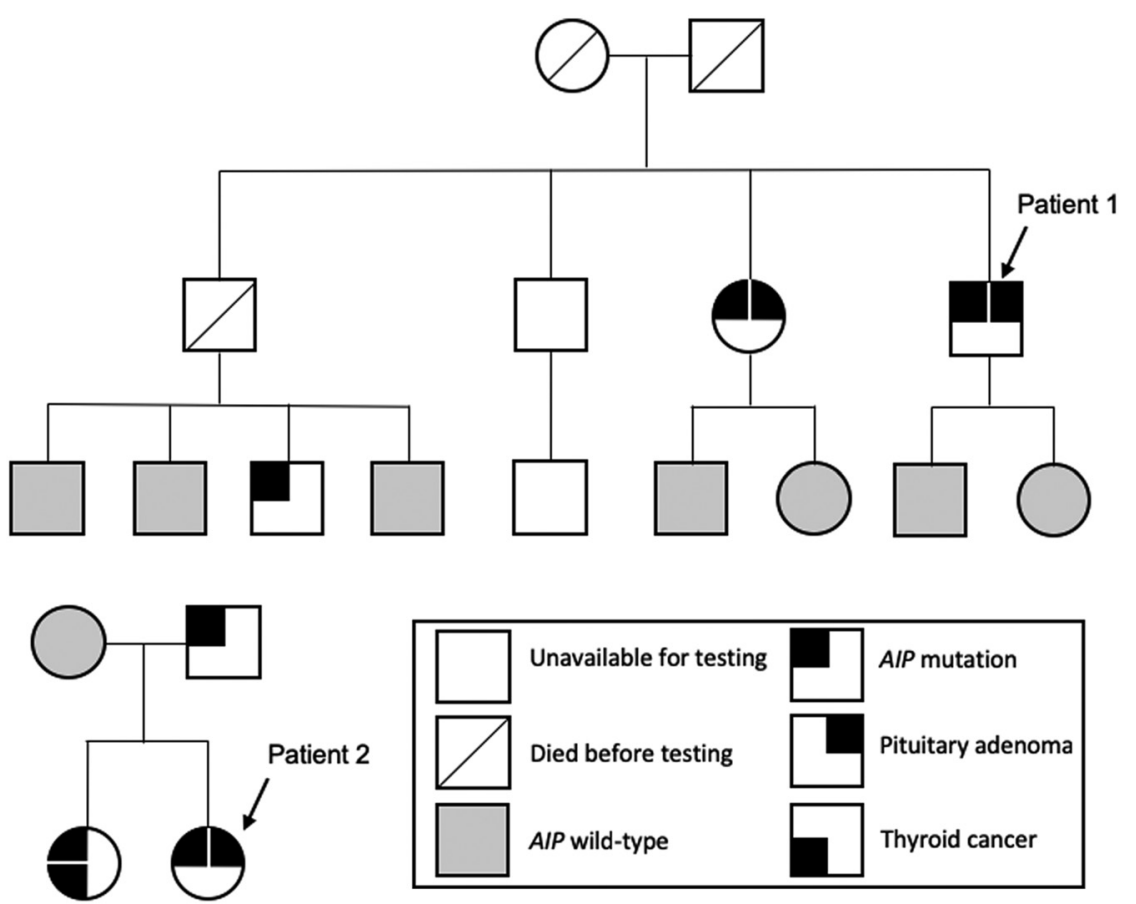

Figure 1

Genealogic trees of Patient 1 and Patient 2. The nephew of Patient 1 who was positive for an AIP mutation is unaffected by pituitary or other diseases; deceased members in the kindred of Patient 1 died for reasons unrelated to pituitary or endocrine diseases. The AIP mutation positive father of Patient 2 is unaffected by pituitary or other endocrine conditions. https://ec.bioscientifica.com https://doi.org/10.1530/EC-19-0004 (c) 2019 The authors Published by Bioscientifica Ltd

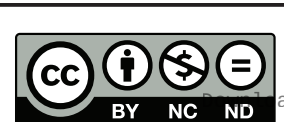

This work is licensed under a Creative Commons Attribution-NonCommercial-NoDerivatives 4.0 Internationab ticense.ifica.com at 04/26/2023 01:53:25PM 


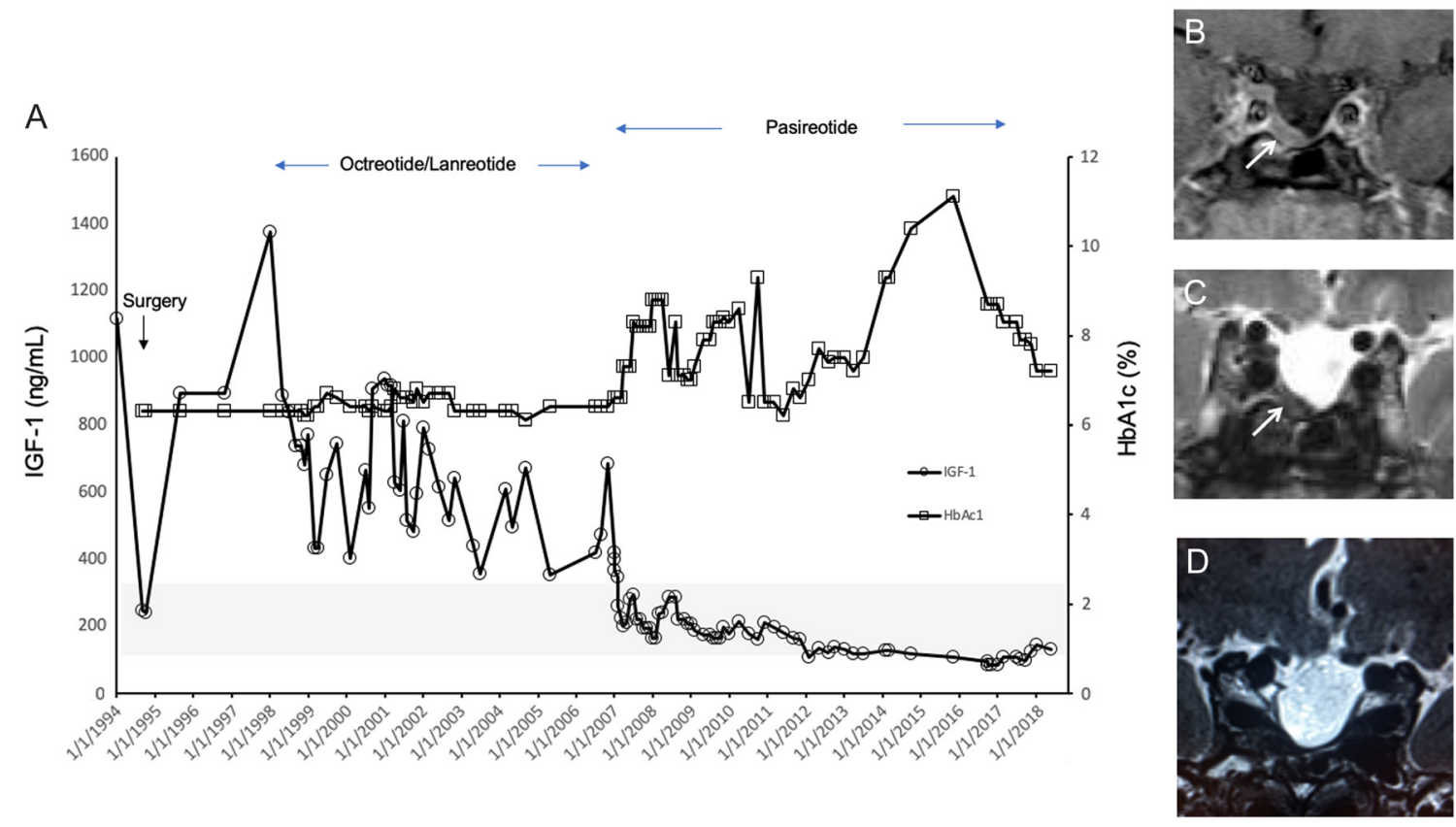

\section{Figure 2}

Panel A shows hormonal responses over 24 years from diagnosis to last follow-up in November 2018 in Patient 1. IGF-1 and HbA1c levels are shown in response to octreotide/lanreotide depots and then with pasireotide LAR beginning in 2006, until withdrawn 18 months ago. The normal range for IGF-1 is outlined in grey in the lower part of the graph. The postoperative tumor residue is shown in panel $\mathrm{B}(\mathrm{arrow})$ and the shrinkage of the tumor in panel $\mathrm{C}$ after about five years of pasireotide therapy. Panel D shows the MRI after $>12$ months off all somatostatin analogs.

addition of insulin glargine. With chronic treatment using pasireotide LAR $40 \mathrm{mg} / \mathrm{month}$, IGF-1 levels continually trended downwards to below the lower limit of normal for age and sex. Given that the tumor remnant had also shrunk with pasireotide LAR, it was decided to reduce the pasireotide dose to bring the IGF-1 into the normal range again. Hence, pasireotide LAR was stopped after 11 years of continual treatment and anti-diabetic medication was reduced concomitantly. Remarkably, after more than 18 months off pasireotide LAR, the IGF-1 has remained in the middle of the normal range, acromegaly symptoms are controlled and no tumor recurrence/regrowth has been seen on MRI (Fig. 2A and D). Diabetes medication has returned to pre-pasireotide baseline treatment with metformin and the last HbA1c was 7.2\%; no evidence of cardiac disease, thyroid disease or colonic polyps was found on surveillance.

The family history of the patient was informative, in that his sister was also diagnosed with acromegaly (aged 24 years), but she was cured after a complete resection of her pituitary macroadenoma (Fig. 1). The kindred formed part of the initial patient group that led to the proposal of FIPA as a disease as MEN1 and Carney complex were ruled out clinically/genetically. With the discovery of AIP gene as a pituitary adenoma predisposition gene, Patient 1 and his sister were found to have a c.649C>T (p.Gln217X) truncating mutation (18). Sequencing of all six exons and intronic boundaries of AIP gene was performed as previously described (19). Extensive family screening identified only one mutation carrier who remains asymptomatic on regular screening (including hormonal testing and a normal baseline MRI) $>12$ years later.

\section{Patient 2}

In 2008, a 16-year-old female attended her physician due to primary amenorrhea and weight gain. She was found to have hyperlipidemia and insulin resistance and dietary modifications were made. Menarche occurred at the age of 17 years and thereafter she suffered from oligomenorrhea. Subsequent investigation revealed hyperprolactinemia (68 ng/mL (NR 1.9-24) ng/mL) and an $8 \times 5 \mathrm{~mm}$ pituitary adenoma was identified (Fig. 3). She was diagnosed with a prolactinoma; cabergoline $(0.5 \mathrm{mg} /$ week) was started and normalized the prolactin, but the tumor was unchanged on MRI 12 months later. The patient was abroad without endocrine follow-up for more than a year. On her return, she exhibited weight gain, had grown by four centimeters in height $(183 \mathrm{~cm} ;+3.06 \mathrm{SDS} ; 20 \mathrm{~cm}$ over mid-parental height) and had headaches, amenorrhea, acromegalic

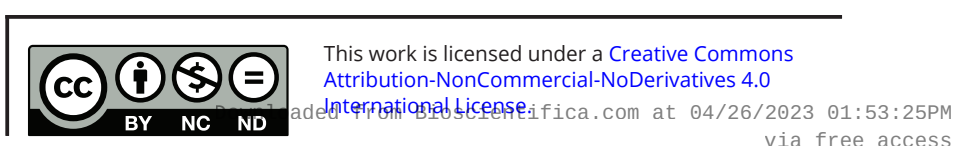




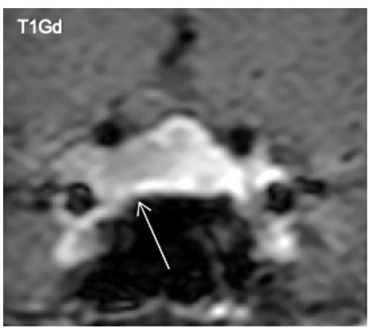

2008

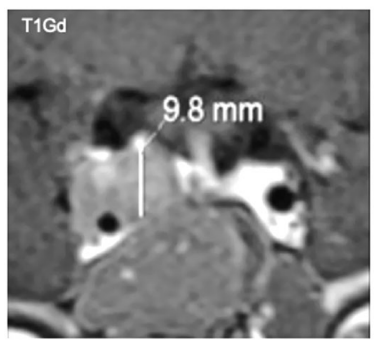

2013

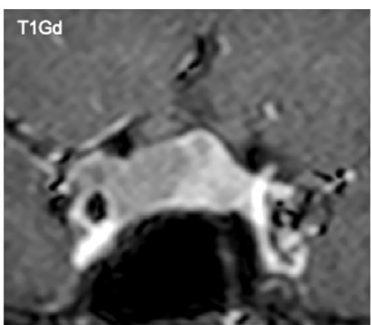

2009

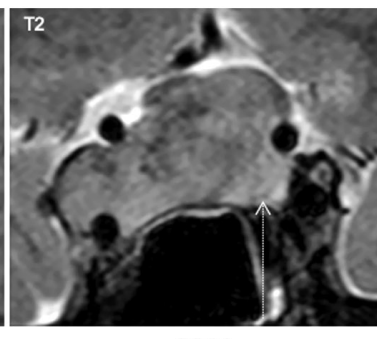

2011

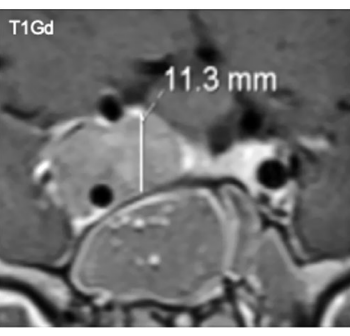

2012

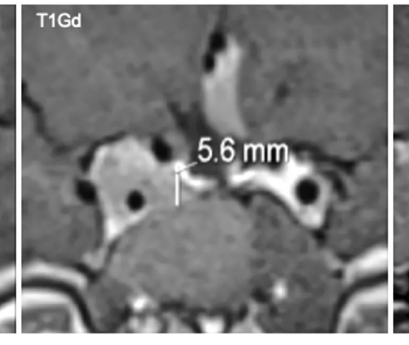

2014

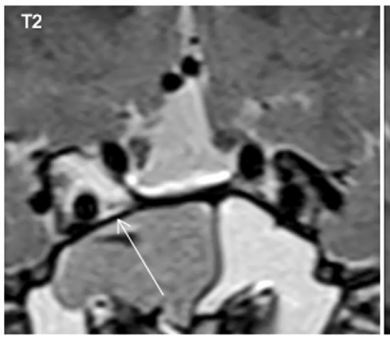

2016

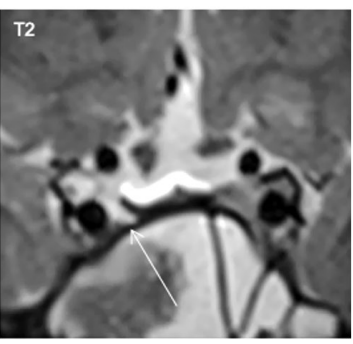

2018

\section{Figure 3}

Trends in growth and shrinkage of the pituitary adenoma in Patient 2. A T1-weighted gadolinium-enhanced (T1Gd) MRI image of the tumor at diagnosis (2008) is shown by the arrow. At that time, it was a microadenoma and prolactin hypersecretion had been established. Slow progression until the 2009 MRI is in marked contrast with the MRI in 2011, when a T2-weighted image shows a large, invasive pituitary macroadenoma had developed, in association with frank signs and symptoms of acromegaly and increased height. Postoperatively, a sizable residue in seen from 2012, but this shrank progressively when the patient was on pasireotide LAR therapy up until the 2016 and 2018 MRI images where there remains evidence of only a small potential tumor residue (arrow).

features, galactorrhea and acanthosis nigricans. She had an elevated baseline GH of $15.7 \mathrm{ng} / \mathrm{mL}$ and an IGF- 1 of $1188 \mathrm{ng} / \mathrm{mL}$ (age-related normal range: $138-442 \mathrm{ng} / \mathrm{mL}$ ); she had stopped cabergoline some months previously and her prolactin was raised at $86 \mathrm{ng} / \mathrm{mL}$. A diagnosis of acromegaly was made and a repeat MRI showed a marked increase in her adenoma, which was now a $37 \times 25 \times 20 \mathrm{~mm}$ invasive macroadenoma impinging on the optic chiasm (Fig. 3). She was referred to a specialist pituitary center and a partial transsphenoidal neurosurgical resection was performed, which confirmed a pituitary adenoma (Ki-67: 3\%) that was strongly positive for GH and prolactin and weakly FSH positive. She underwent a second neurosurgical intervention to further debulk her tumor.

Postoperatively, Patient 2 had residual tumor tissue and uncontrolled GH $(7.7 \mathrm{ng} / \mathrm{mL})$ and IGF-1 $(888 \mathrm{ng} / \mathrm{mL})$ levels. She underwent two acute tests, one with octreotide $100 \mu \mathrm{g}$ s.c. and one with pasireotide $600 \mu \mathrm{g}$ s.c. The octreotide test led to no change in GH, while the pasireotide test diminished GH from a baseline of 9.5 to $3.3 \mathrm{ng} / \mathrm{mL}$ after $4 \mathrm{~h}$. She was started on pasireotide LAR $20 \mathrm{mg}$ i.m. every 4 weeks and this was up-titrated to $60 \mathrm{mg}$ over 12 months and during this time her IGF-1 was normalized $(203 \mathrm{ng} / \mathrm{mL})$. Symptomatically the patient reported improvements. Her HbA1c before starting pasireotide LAR was $5.8 \%$, and this rose (7.3\%) during pasireotide LAR treatment and she was started on metformin. With continued pasireotide LAR treatment, HbA1c continued to rise and insulin treatment was instituted; over the same period IGF-1 fell below the lower limit of normal and a decision was made to switch to octreotide LAR $40 \mathrm{mg} / \mathrm{month}$ i.m. Over a 3-month period, IGF-1 became uncontrolled, rising from 90 to $503 \mathrm{ng} / \mathrm{mL}$ and HbA1c fell slightly to $6.3 \%$. Due to this rapid loss of hormonal control, pasireotide LAR was restarted at a dose of $40 \mathrm{mg} / \mathrm{month}$, which was up-titrated to $60 \mathrm{mg} / \mathrm{month}$ after six months and IGF-1 was controlled again $(235 \mathrm{ng} / \mathrm{mL})$. Restarting pasireotide LAR was associated with worsening of the diabetic control and HbA1c rose to $11.5 \%$ and required treatment with metformin, dapagliflozin, extendin and gliclazide. Serial MRI during the period of pasireotide LAR treatment showed a gradual and significant reduction in the residual tumor size by the end of the third year of pasireotide LAR treatment (Fig. 3). At last follow-up after more than 6 years of pasireotide LAR therapy, her IGF-1 was normal $(165 \mathrm{ng} / \mathrm{mL})$ and her tumor remnant was very small. Diabetes remained difficult to control (HbA1c: 9.2\%) on multiple therapies (dulaglutide, metformin, empagliflozin and gliclazide); she had ongoing problems with obesity (bariatric surgery was planned) and a diagnosis of non-alcoholic steatohepatitis (NASH) was established. 
Investigations of acromegaly-associated complications revealed colon polyposis (no malignancy), normal echography of the heart and no thyroid nodules.

Given the patient's history of an early onset, invasive GH-secreting macroadenoma occurring in her teens, she was referred for genetic testing before her first surgery, which revealed a novel germline AIP mutation, c.343delC (p.(Leu115Trpfs*41)), that led to a predicted early truncation of the protein. The family history was positive for an older sister who had a $2.5 \mathrm{~cm}$ invasive follicular thyroid carcinoma diagnosed and successfully treated by total thyroidectomy and radioiodine at the age of 21 years (Fig. 1). Genetic testing in the family revealed that the sister with thyroid cancer was also an AIP mutation carrier, as was the unaffected father. Further testing of the pituitary tissue from Patient 2 and of the thyroid tumor tissue from her sister revealed loss of heterozygosity at the AIP locus, indicating a second hit had taken place in both pituitary and thyroid tumors. Immunohistochemistry of the follicular thyroid cancer showed no AIP staining (Fig. 4). Similarly, the pituitary adenoma in Patient 2 had low or absent AIP staining on immunohistochemistry (Fig. 4). Further immunostaining demonstrated that SST2 was virtually absent throughout the pituitary tumor, whereas SST5 staining was positive but quite variable in different sampling regions of the somatotropinoma. SST3 staining was high (Fig. 5).

\section{Discussion}

Pasireotide is a somatostatin analog with activity at multiple SSTs, which binds preferentially to SST5 and SST2 (20). In the clinical setting, pasireotide is used in either short-acting or long-acting depot formulations for the treatment of Cushing's disease and acromegaly $(21,22)$. In acromegaly, pasireotide LAR is indicated for patients that have failed previous therapy with SST2-specific drugs, such as octreotide and lanreotide. When compared with the SST2-specific agents, switching to pasireotide has been shown to improve control of acromegaly in resistant patients (23). Patients with germline AIP mutations are one of the few well-characterized forms of SST2-specific SSA resistance in acromegaly and such patients can have the dual problem of incomplete hormonal control and a lack of clinically meaningful pituitary tumor shrinkage (9). To date, however, there has been no specific information on the use of pasireotide LAR in treating patients with octreotide/lanreotide resistance due to germline AIP mutations.

Here, we show that long-term pasireotide LAR treatment can provide control of GH, IGF-1 and induce significant tumor shrinkage in two unrelated AIP-mutated acromegaly cases treated for 6-11 years. The clinical experience in these two cases mirrors that of good responders to pasireotide LAR from clinical trials. Insufficient hormonal control with octreotide/lanreotide in acromegaly can be improved by switching to pasireotide, as was seen in Patient 1. He was left with an unresectable residue postoperatively, which proved resistant to octreotide and lanreotide depots. In parallel with the hormonal control under pasireotide LAR, tumor shrinkage also occurred over the long term. Despite withdrawal of pasireotide LAR for more than 18 months, tumor tissue has not regrown. Given that hormonal control has also endured while off pasireotide LAR, it suggests that the residue has undergone involution. Patient 1 was never treated with radiotherapy, so the most

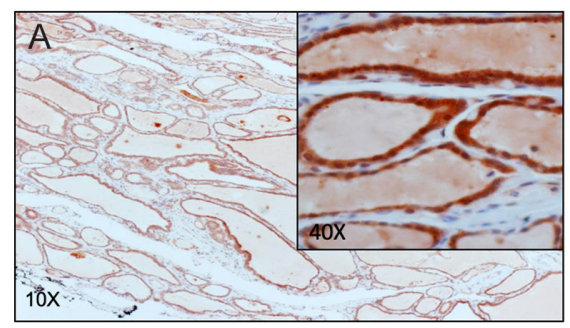

Normal thyroid AIP staining (brown, high intensity)

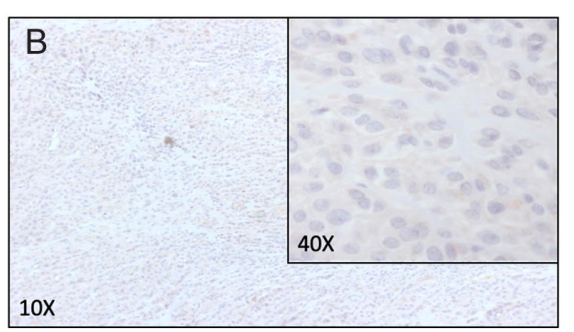

Follicular thyroid cancer AIP staining (moderate, scattered)

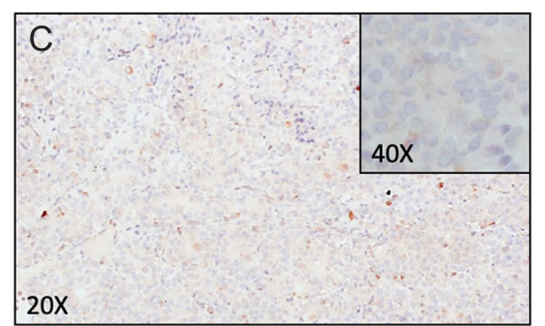

AIP staining in pituitary adenoma (low/absent)

\section{Figure 4}

AIP immunostaining in tumors from Patient 2 and family. Panel A shows normal thyroid tissue with strong positivity for AIP (brown) from the AIP mutation-positive sister of Patient 2 who had a $2.5 \mathrm{~cm}$ follicular thyroid carcinoma at a young age. In panel B the AIP staining of the follicular thyroid carcinoma is generally negative or scant. Panel C shows the absent or low AIP immunostaining in the somatotropinoma of Patient 2 at $20 \times$ and $40 \times$ resolutions.

(c) 2019 The authors Published by Bioscientifica Ltd

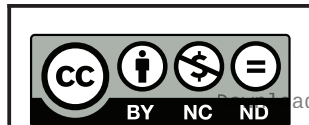

This work is licensed under a Creative Commons Attribution-NonCommercial-NoDerivatives 4.0 Internationab ticense.ifica.com at 04/26/2023 01:53:25PM 
SST2
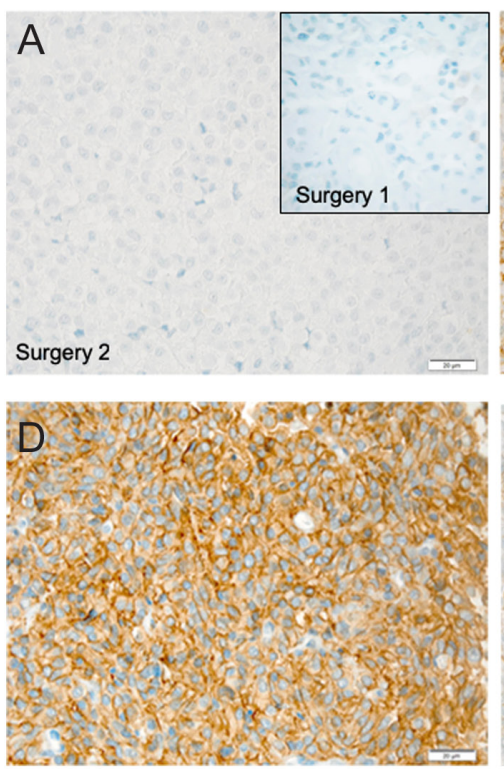

SST3
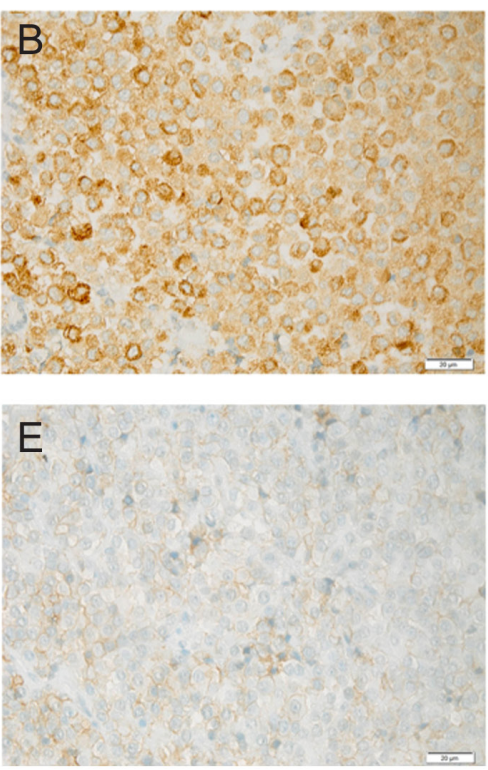

SST5
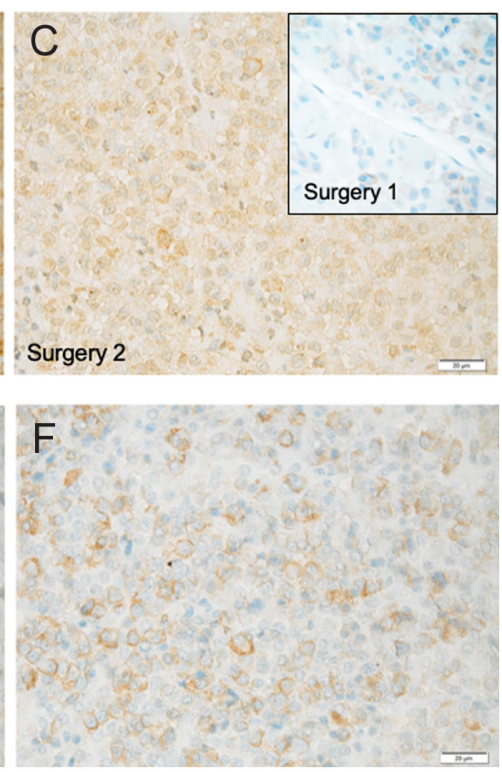

Figure 5

Somatostatin receptor (SST) immunohistochemistry in the pituitary adenoma from Patient 2 and control acromegaly case. Panels A, B and C show the SST2, SST3 and SST5 staining in the somatotropinoma from Patient 2. Staining of two tumor samples for SST2 and SST5 are shown in panels A and C (surgery 1 inset; surgery 2 main picture), demonstrating negative SST2 staining and variably positive SST5 staining, predominantly membranous. SST3 staining (panel B) was strongly positive. For comparison purposes, panels D, E and F show examples of SST2, SST3 and SST5 staining, respectively in tumor from a representative octreotide-responsive AIP mutation-negative adult acromegaly patient.

likely explanation currently is that chronic pasireotide LAR was responsible. The mechanism by which this involution occurred is unknown but we suggest that activation of SST5-predominant anti-proliferative and pro-apoptotic pathways as seen in corticotropes could also be involved in somatotropinomas with disordered AIP function $(24,25)$. Patient 2 has had a shorter duration of pasireotide LAR treatment overall, but as seen in Fig. 3, continuing treatment over 6 years led to very marked tumor shrinkage and long-term IGF-1 control. In both of the cases described here, the pasireotide-induced tumor shrinkage occurred in difficult to reach regions, which is a clinically meaningful benefit.

Unlike Patient 1 who was diagnosed in 1994, Patient 2 was diagnosed after the role of AIP mutations in the etiopathology of young-onset aggressive acromegaly had been recognized. Patient 2 provides a rare insight into the natural history of the development of an AIP mutationpositive pituitary adenoma. The first diagnosis was one of a microprolactinoma; the accompanying clinical symptoms (menstrual disturbance) and hyperprolactinemia meant that acromegaly was not suspected initially. Over the first year after diagnosis the tumor did not undergo significant growth and cabergoline treatment may have contributed to this. However, in parallel with the onset of clear
GH/IGF-1 driven acromegalic symptoms and increased vertical growth, the tumor grew significantly to become an invasive macroadenoma. Indeed, by the time of her somatotropinoma diagnosis she was already well in excess of her mid-parental height, which suggests strongly that her tumor had long established GH hypersecretion. This snapshot of the early progression of an AIP mutationrelated pituitary adenoma suggests that tumor growth may not be uniform and that some other feature of the tumor alters behavior and growth quite rapidly. It may be that continued tumor proliferation is associated with accumulation of new genetic changes that themselves induce more aggressive expansion. In that setting AIP mutations could act as a driver mutation but also work in concert with other mutations or copy number variations to produce the final phenotype of large, invasive, somatostatin analog resistant pituitary adenomas. In line with this we previously showed that loss of heterozygosity - indicative of a second hit at the AIP locus - was a later event than hyperplasia in the macroadenomas of two sisters with germline AIP mutations (26).

At the time of diagnosis of Patient 2, it was recognized that resistance to first-generation somatostatin analogs was a characteristic of AIP mutation positive acromegaly
This work is licensed under a Creative Commons Attribution-NonCommercial-NoDerivatives 4.0 elpternationab bicense.ifica. com at 04/26/2023 01:53:25PM 
(9). Hence, the patient had test doses of subcutaneous pasireotide and octreotide. The role of such test dosing to predict responses to long-term octreotide/lanreotide treatment is controversial, but similar studies of pasireotide test dosing have not been performed widely. Although it is not a standard approach, when considering switching to pasireotide in octreotide-resistant patients, the use of a test dose might be informative, at least in AIP-mutated patients. In Patient 2, we later found no clinical response to a first-generation compound when switched from pasireotide LAR to octreotide LAR for three months, indicating the test dose approach was helpful in this case. In addition, SST immunohistochemistry showed absent SST2 staining and moderate membranous SST5 staining; this further argued in favor of using pasireotide LAR as it is not an SST2 dependent compound. Recently Yamamoto et al. reported the case of an AIP mutationnegative acromegaly patient who had a negative response to an octreotide test dose (paradoxical rise in GH) (27). That patient had other features suggestive of poorer first-generation SSA responses, including tumor hyperintensity on T2-weighted images (28). Yamamoto et al. found good tumoral and hormonal responses to pasireotide and subsequent surgery showed the tumor to be negative for AIP immunostaining and to have a low level of SST2 vs SST5 staining. Previous studies in AIP-mutated and non-mutated acromegaly cases have emphasized the importance of AIP immunohistochemical staining intensity in the responsiveness to first-generation somatostatin analogs $(29,30,31,32)$. Somatostatin analogs themselves can potentially alter AIP expression and actions via molecules such as ZAC1, a key factor in SST2-mediated effects of octreotide $(12,13,33)$. Recently, Iacovazzo et al. reported that the only predictor of pasireotide responsiveness in octreotide/lanreotideresistant patients was the presence of SST5 (34). Should the molecular profile of AIP-mutated pituitary adenomas give rise to a greater likelihood of low AIP/SST2 protein expression coupled with membranous SST5, this might explain the relative resistance to first-generation SSA and argue for the specific use of pasireotide as tailored medical therapy for some patients with AIP mutations.

The aggressive nature of pituitary adenomas in those with AIP mutations raises a series of challenges for clinical management. As tumors are generally large and are often invasive at diagnosis, primary neurosurgical cure, as occurred in the sister of Patient 1, is unfortunately, the exception. Furthermore, unlike in acromegaly in general where it is usually helpful, surgical debulking in AIP mutated acromegaly cases is not guaranteed to increase control with postoperative SSA $(9,35,36)$. Patients with AIP mutations also are generally young at disease onset, and these patients are at risk of increased vertical growth leading to pituitary gigantism, of which AIP mutations are the leading genetic cause (37). In pituitary gigantism, early hormonal control is associated with decreased final height so the instigation of effective therapy is key (38). Use of pegvisomant in combination with first-generation somatostatin analogs has proven effective in young AIP-mutated patients, including those with pituitary gigantism $(14,39)$.

AIP mutations are usually seen in the setting of FIPA or gigantism and are not known to associate with other non-pituitary tumor types even though AIP is a widely expressed protein (8). While thyroid nodules are common in acromegaly, coexistence of differentiated thyroid carcinoma in AIP-mutated acromegaly patients is very rare (40). The case of the follicular thyroid cancer in the AIP mutation-positive sister of Patient 2 is, therefore, very unusual. She was diagnosed with a $2.5 \mathrm{~cm}$ minimally invasive follicular thyroid carcinoma (T2NOMx) of the right lobe and was cured by total thyroidectomy and radioactive iodine ablation at the age of 21 years. This carcinoma occurred at a much younger age than is typical for follicular thyroid cancer, which has a peak incidence between 40 and 60 years of age. Raitila et al. reported that AIP mutations do not predispose to familial non-medullary thyroid cancer (papillary and follicular), and a follicular thyroid cancer from a patient with a family history of AIP mutation was found not to have any disordered AIP immunohistochemical staining or loss of heterozygosity in their thyroid tumor (41). Unlike that case, the patient we describe had decreased AIP staining in the tumor tissue as compared with her own normal thyroid gland, and there was evidence of loss of heterozygosity at the AIP locus in the tumor DNA. It is, however, important, to note that follicular thyroid cancers frequently (up to $14 \%)$ have genomic loss at chromosome $11 \mathrm{q} 13$, so the role of the AIP mutation as an initiating event is open to question $(42,43)$. Further studies of AIP expression and AIP genetic status among follicular thyroid cancer cohorts might be warranted.

As expected in acromegaly patients with impaired glucose tolerance or diabetes mellitus at baseline, pasireotide LAR treatment was associated with worsening of glucose metabolism. This is an established feature of pasireotide treatment in preclinical and clinical studies of acromegaly $(44,45)$. We noted that both cases
This work is licensed under a Creative Commons Attribution-NonCommercial-NoDerivatives 4.0 Internationab License.ifica com at $04 / 26 / 2023$ 01:53:25PM 
developed marked elevations in HbA1c and this required multi-modal therapy and control was only achieved following the addition of insulin and GLP-1 agonists. The added burden of injectable and oral medical therapies due to diabetes mellitus has to be balanced against the excellent clinical, hormonal and tumoral responses that occurred with chronic pasireotide LAR. Given the resistant disease profile due to AIP mutations in these two patients, no other effective options were available that could produce both the complete hormonal control and impressive tumor shrinkage that were seen with pasireotide LAR.

In conclusion, pasireotide LAR treatment for up to 11 years was associated with hormonal control and marked tumor shrinkage in the setting of octreotide/lanreotideresistant acromegaly due to germline AIP mutations. The magnitude and durability of the responses included tumoral and hormonal control for more than 18 months even after withdrawing pasireotide LAR in one patient. The profile of AIP-mutated somatotropinomas is one of early-onset and aggressive disease and challenging clinical management due to tumors that are poorly responsive to first-generation SSA, possibly due to low/absent SST2 and AIP expression. Pasireotide, with its affinity for multiple somatostatin receptors, could represent a tailored medical approach in some octreotide/lanreotide resistant acromegaly patients with AIP mutations.

\section{Declaration of interest}

The authors declare that there is no conflict of interest that could be perceived as prejudicing the impartiality of the research reported.

\section{Funding}

This study was supported by a grant from the Fonds d'Investissement pour la Recherche Scientifique of the $\mathrm{CHU}$ de Liège and by a grant from the JABBS Foundation, UK.

\section{References}

1 Caputo M, Ucciero A, Mele C, De Marchi L, Magnani C, Cena T, Marzullo P, Barone-Adesi F \& Aimaretti G. Use of administrative health databases to estimate incidence and prevalence of acromegaly in Piedmont Region, Italy. Journal of Endocrinological Investigation 2018 [epub]. (https://doi.org/10.1007/s40618-0180928-7)

2 Gruppetta M, Mercieca C \& Vassallo J. Prevalence and incidence of pituitary adenomas: a population based study in Malta. Pituitary 201316 545-553. (https://doi.org/10.1007/s11102-012-0454-0)

3 Gatto F, Trifirò G, Lapi F, Cocchiara F, Campana C, Dell'Aquila C, Ferrajolo C, Arvigo M, Cricelli C, Giusti M, et al. Epidemiology of acromegaly in Italy: analysis from a large longitudinal primary care database. Endocrine 201861 533-541. (https://doi.org/10.1007/ s12020-018-1630-4)
4 Daly AF, Rixhon M, Adam C, Dempegioti A, Tichomirowa MA $\&$ Beckers A. High prevalence of pituitary adenomas: a crosssectional study in the province of Liège, Belgium. Journal of Clinical Endocrinology and Metabolism 200691 4769-4775. (https://doi. org/10.1210/jc.2006-1668)

5 Petrossians P, Daly AF, Natchev E, Maione L, Blijdorp K, SahnounFathallah M, Auriemma R, Diallo AM, Hulting AL, Ferone D, et al. Acromegaly at diagnosis in 3173 patients from the Liège Acromegaly Survey (LAS) database. Endocrine-Related Cancer 201724 505-518. (https://doi.org/10.1530/ERC-17-0253)

6 Mantovani G, Lania AG \& Spada A. GNAS imprinting and pituitary tumors. Molecular and Cellular Endocrinology 2010326 15-18. (https://doi.org/10.1016/j.mce.2010.04.009)

7 Rostomyan L, Daly AF \& Beckers A. Pituitary tumors associated with multiple endocrine neoplasia syndromes. Encyclopedia of Endocrine Diseases 20191 642-647. (https://doi.org/10.1016/B978-0-12801238-3.66169-X)

8 Daly AF \& Beckers A. Familial isolated pituitary adenomas (FIPA) and mutations in the aryl hydrocarbon receptor interacting protein (AIP) gene. Endocrinology and Metabolism Clinics of North America 201544 19-25. (https://doi.org/10.1016/j.ecl.2014.10.002)

9 Daly AF, Tichomirowa MA, Petrossians P, Heliövaara E, JaffrainRea ML, Barlier A, Naves LA, Ebeling T, Karhu A, Raappana A, et al. Clinical characteristics and therapeutic responses in patients with germ-line AIP mutations and pituitary adenomas: an international collaborative study. Journal of Clinical Endocrinology and Metabolism 201095 E373-E383. (https://doi.org/10.1210/jc.2009-2556)

10 Hernández-Ramírez LC, Gabrovska P, Dénes J, Stals K, Trivellin G, Tilley D, Ferrau F, Evanson J, Ellard S, Grossman AB, et al. Landscape of familial isolated and young-onset pituitary adenomas: prospective diagnosis in AIP mutation carriers. Journal of Clinical Endocrinology and Metabolism 2015100 E1242-E1254. (https://doi.org/10.1210/ jc.2015-1869)

11 Tuominen I, Heliövaara E, Raitila A, Rautiainen MR, Mehine M, Katainen R, Donner I, Aittomäki V, Lehtonen HJ, Ahlsten M, et al. AIP inactivation leads to pituitary tumorigenesis through defective Goi-cAMP signaling. Oncogene 201534 1174-1184. (https://doi. org/10.1038/onc.2014.50)

12 Chahal HS, Trivellin G, Leontiou CA, Alband N, Fowkes RC, Tahir A Igreja SC, Chapple JP, Jordan S, Lupp A, et al. Somatostatin analogs modulate AIP in somatotroph adenomas : the role of the ZAC1 pathway. Journal of Clinical Endocrinology and Metabolism 201297 1-10. (https://doi.org/10.1210/jc.2012-1111)

13 Theodoropoulou M, Tichomirowa MA, Sievers C, Yassouridis A, Arzberger T, Hougrand O, Deprez M, Daly AF, Petrossians P, Pagotto U, et al. Tumor ZAC1 expression is associated with the response to somatostatin analog therapy in patients with acromegaly. International Journal of Cancer 2009125 2122-2126. (https://doi.org/10.1002/ijc.24602)

14 Joshi K, Daly AF, Beckers A \& Zacharin M. Resistant paediatric somatotropinomas due to AIP mutations: role of pegvisomant. Hormone Research in Paediatrics 201890 196-202. (https://doi. org/10.1159/000488856)

15 Ben-Shlomo A \& Melmed S. Pasireotide - a somatostatin analog for the potential treatment of acromegaly, neuroendocrine tumors and Cushing's disease. IDrugs 200710 885-895.

16 Gadelha MR, Wildemberg LE, Bronstein MD, Gatto F \& Ferone D. Somatostatin receptor ligands in the treatment of acromegaly. Pituitary 201720 100-108. (https://doi.org/10.1007/s11102-0170791-0)

17 Körner M, Waser B, Christ E, Beck J \& Reubi JC. A critical evaluation of sst3 and sst5 immunohistochemistry in human pituitary adenomas. Neuroendocrinology 2018106 116-127. (https://doi. org/10.1159/000472563)

18 Daly AF, Vanbellinghen JF, Khoo SK, Jaffrain-Rea ML, Naves LA, Guitelman MA, Murat A, Emy P, Gimenez-Roqueplo AP, 
Tamburrano G, et al. Aryl hydrocarbon receptor-interacting protein gene mutations in familial isolated pituitary adenomas: analysis in 73 families. Journal of Clinical Endocrinology and Metabolism 200792 1891-1896. (https://doi.org/10.1210/jc.2006-2513)

19 Salvatori R, Daly AF, Quinones-Hinojosa A, Thiry A \& Beckers A. A clinically novel AIP mutation in a patient with a very large, apparently sporadic somatotrope adenoma. Endocrinology, Diabetes and Metabolism Case Reports 20142014 140048. (https://doi. org/10.1530/EDM-14-0048)

20 Schmid HA. Pasireotide (SOM230): development, mechanism of action and potential applications. Molecular and Cellular Endocrinology 2008286 69-74. (https://doi.org/10.1016/j.mce.2007.09.006)

21 Boscaro M, Ludlam WH, Atkinson B, Glusman JE, Petersenn S, Reincke M, Snyder P, Tabarin A, Biller BM, Findling J, et al. Treatment of pituitary-dependent Cushing's disease with the multireceptor ligand somatostatin analog pasireotide (SOM230): a multicenter, phase II trial. Journal of Clinical Endocrinology and Metabolism 200994 115-122. (https://doi.org/10.1210/jc.2008-1008)

22 Petersenn S, Schopohl J, Barkan A, Mohideen P, Colao A, Abs R, Buchelt A, Ho YY, Hu K, Farrall AJ, et al. Pasireotide (SOM230) demonstrates efficacy and safety in patients with acromegaly: a randomized, multicenter, phase II trial. Journal of Clinical Endocrinology and Metabolism 201095 2781-2789. (https://doi. org/10.1210/jc.2009-2272)

23 Bronstein MD, Fleseriu M, Neggers S, Colao A, Sheppard M, Gu F, Shen CC, Gadelha M, Farrall AJ, Hermosillo Reséndiz K, et al. Switching patients with acromegaly from octreotide to pasireotide improves biochemical control: crossover extension to a randomized, double-blind, Phase III study. BMC Endocrine Disorders 20161616. (https://doi.org/10.1186/s12902-016-0096-8)

24 Treppiedi D, Giardino E, Catalano R, Mangili F, Vercesi P, Sala E, Locatelli M, Arosio M, Spada A, Mantovani G, et al. Somatostatin analogs regulate tumor corticotrophs growth by reducing ERK1/2 activity. Molecular and Cellular Endocrinology 2019483 31-38. (https://doi.org/10.1016/j.mce.2018.12.022)

25 Gatto F, Arvigo M, Amarù J, Campana C, Cocchiara F, Graziani G, Bruzzone E, Giusti M, Boschetti M \& Ferone D. Cell specific interaction of pasireotide: review of preclinical studies in somatotroph and corticotroph pituitary cells. Pituitary 201922 89-99. (https://doi.org/10.1007/s11102-018-0926-y)

26 Villa C, Lagonigro MS, Magri F, Koziak M, Jaffrain-Rea ML, Brauner R, Bouligand J, Junier MP, Di F, Sainte-Rose C, et al. Hyperplasiaadenoma sequence in pituitary tumorigenesis related to aryl hydrocarbon receptor interacting protein gene mutation. EndocrineRelated Cancer 201118 347-356. (https://doi.org/10.1530/ERC-110059)

27 Yamamoto R, Robert Shima K, Igawa H, Kaikoi Y, Sasagawa Y, Hayashi Y, Inoshita N, Fukuoka H, Takahashi Y \& Takamura T. Impact of preoperative pasireotide therapy on invasive octreotideresistant acromegaly. Endocrine Journal 201865 1061-1067. (https:// doi.org/10.1507/endocrj.EJ17-0487)

28 Potorac I, Petrossians P, Daly AF, Alexopoulou O, Borot S, Sahnoun Fathallah M, Castinetti F, Devuyst F, Jaffrain Rea ML, Briet C, et al. T2-weighted MRI signal predicts hormone and tumor responses to somatostatin analogs in acromegaly. Endocrine-Related Cancer 2016 23 871-881. (https://doi.org/10.1530/ERC-16-0356)

29 Jaffrain-Rea ML, Rotondi S, Turchi A, Occhi G, Barlier A, Peverelli E, Rostomyan L, Defilles C, Angelini M, Oliva MA, et al. Somatostatin analogues increase AIP expression in somatotropinomas, irrespective of Gsp mutations. Endocrine-Related Cancer 201320 753-766. (https://doi.org/10.1530/ERC-12-0322)

30 Jaffrain-Rea ML, Angelini M, Gargano D, Tichomirowa MA, Daly AF, Vanbellinghen JF, D'Innocenzo E, Barlier A, Giangaspero F, Esposito V, et al. Expression of aryl hydrocarbon receptor (AHR) and AHR-interacting protein in pituitary adenomas: pathological and clinical implications. Endocrine-Related Cancer 200916 1029-1043. (https://doi.org/10.1677/ERC-09-0094)

31 Kasuki L, Vieira Neto L, Wildemberg LE, Colli LM, De Castro M, Takiya CM \& Gadelha MR. AIP expression in sporadic somatotropinomas is a predictor of the response to octreotide LAR therapy independent of SSTR2 expression. Endocrine-Related Cancer 201219 L25-L29. (https://doi.org/10.1530/ERC-12-0020)

32 Kasuki Jomori de Pinho L, Vieira Neto L, Armondi Wildemberg LE, Gasparetto EL, Marcondes J, de Almeida Nunes B, Takiya CM \& Gadelha MR. Low aryl hydrocarbon receptor-interacting protein expression is a better marker of invasiveness in somatotropinomas than Ki-67 and p53. Neuroendocrinology 201194 39-48. (https://doi. org/10.1159/000322787)

33 Theodoropoulou M, Zhang J, Laupheimer S, Paez-Pereda M, Erneux C, Florio T, Pagotto U \& Stalla GK. Octreotide, a somatostatin analogue, mediates its antiproliferative action in pituitary tumor cells by altering phosphatidylinositol 3-kinase signaling and inducing Zac1 expression. Cancer Research 200666 1576-1582. (https://doi. org/10.1158/0008-5472.CAN-05-1189)

34 Iacovazzo D, Carlsen E, Lugli F, Chiloiro S, Piacentini S, Bianchi A, Giampietro A, Mormando M, Clear AJ, Doglietto F, et al. Factors predicting pasireotide responsiveness in somatotroph pituitary adenomas resistant to first-generation somatostatin analogues: an immunohistochemical study. European Journal of Endocrinology 2016 174 241-250. (https://doi.org/10.1530/EJE-15-0832)

35 Petrossians P, Borges-Martins L, Espinoza C, Daly A, Betea D, Valdes-Socin H, Stevenaert A, Chanson P \& Beckers A. Gross total resection or debulking of pituitary adenomas improves hormonal control of acromegaly by somatostatin analogs. European Journal of Endocrinology 2005152 61-66. (https://doi.org/10.1530/eje.1.01824)

36 Karavitaki N, Turner HE, Adams CB, Cudlip S, Byrne JV, FazalSanderson V, Rowlers S, Trainer PJ \& Wass JA. Surgical debulking of pituitary macroadenomas causing acromegaly improves control by lanreotide. Clinical Endocrinology 200868 970-975. (https://doi. org/10.1111/j.1365-2265.2007.03139.x)

37 Rostomyan L, Daly AF, Petrossians P, Nachev E, Lila AR, Lecoq AL, Lecumberri B, Trivellin G, Salvatori R, Moraitis AG, et al. Clinical and genetic characterization of pituitary gigantism: an international collaborative study in 208 patients. Endocrine-Related Cancer 201522 745-757. (https://doi.org/10.1530/ERC-15-0320)

38 Beckers A, Petrossians P, Hanson J \& Daly AF. The causes and consequences of pituitary gigantism. Nature Reviews Endocrinology 201814 705-720. (https://doi.org/10.1038/s41574-018-0114-1)

39 Mangupli R, Rostomyan L, Castermans E, Caberg JH, Camperos P, Krivoy J, Cuauro E, Bours V, Daly AF \& Beckers A. Combined treatment with octreotide LAR and pegvisomant in patients with pituitary gigantism: clinical evaluation and genetic screening. Pituitary 201619 507-514. (https://doi.org/10.1007/s11102-0160732-3)

40 Urbani C, Russo D, Raggi F, Lombardi M, Sardella C, Scattina I, Lupi I, Manetti L, Tomisti L, Marcocci C, et al. A novel germline mutation in the aryl hydrocarbon receptor-interacting protein (AIP) gene in an Italian family with gigantism. Journal of Endocrinological Investigation 201437 949-955. (https://doi.org/10.1007/s40618-0140123-4)

41 Raitila A, Georgitsi M, Bonora E, Vargiolu M, Tuppurainen K, Makinen MJ, Vierimaa O, Salmela PI, Launonen V, Vahteristo P, et al. Aryl hydrocarbon receptor interacting protein mutations seem not to associate with familial non-medullary thyroid cancer. Journal of Endocrinological Investigation 200932 426-429. (https://doi. $\operatorname{org} / 10.1007 /$ BF03346480)

42 Matsuo K, Tang SH \& Fagin JA. Allelotype of human thyroid tumors: loss of chromosome 11q13 sequences in follicular neoplasms. Molecular Endocrinology 19915 1873-1879. (https://doi.org/10.1210/ mend-5-12-1873) https://ec.bioscientifica.com https://doi.org/10.1530/EC-19-0004 (c) 2019 The authors Published by Bioscientifica Ltd
This work is licensed under a Creative Commons Attribution-NonCommercial-NoDerivatives 4.0 International License.ifica com at $04 / 26 / 2023$ 01:53:25PM 
43 Nord B, Larsson C, Wong FK, Wallin G, Teh BT \& Zedenius J. Sporadic follicular thyroid tumors show loss of a 200-kb region in 11q13 without evidence for mutations in the MEN1 gene. Genes, Chromosomes and Cancer 199926 35-39. (https://doi.org/10.1002/ (SICI)1098-2264(199909)26:1<35::AID-GCC5>3.0.CO;2-L)

44 Reznik Y, Bertherat J, Borson-Chazot F, Brue T, Chanson P, Cortet-Rudelli C, Delemer B, Tabarin A, Bisot-Locard S \& Vergès B. Management of hyperglycaemia in Cushing's disease: experts' proposals on the use of pasireotide. Diabetes and Metabolism 201339 34-41. (https://doi.org/10.1016/j. diabet.2012.10.005)

45 Tarasco E, Seebeck P, Pfundstein S, Daly AF, Eugster PJ, Harris AG, Grouzmann E, Lutz TA \& Boyle CN. Effect of AP102, a subtype 2 and 5 specific somatostatin analog, on glucose metabolism in rats. Endocrine 201758 124-133. (https://doi.org/10.1007/ s12020-017-1386-2)

Received in final form 27 February 2019

Accepted 8 March 2019

Accepted Preprint published online 8 March 2019 (c) 2019 The authors Published by Bioscientifica Ltd 